\title{
Speak Louder Than the Ballot: A Cognitive Study to Election Abstention Metaphors
}

\author{
Muhammad Adam \\ Universitas Balikpapan, INDONESIA \\ e-mail: adam@uniba-bpn.ac.id
}

\begin{abstract}
This research aims to investigate the metaphorical description of abstention during the Indonesian election 2019 in foreign media news by analyzing the source domains and various metaphor components found in the metaphors. Lakoff's and Johnson's theory is used for revealing the beliefs, attitudes, and ideology behind metaphors. Kövecses' idea (2003), which highlights, the components of metaphor, is also used for examining the essential components in the metaphors analyzed. This study is a qualitative study. It examines five foreign media reports on abstentions in Indonesian elections, which are used as the data for this study. The findings show that the essential components behind the metaphor are mental images, cultural contexts, and elements highlighted in the metaphors. They contribute to the metaphorical function and interpretation. The metaphors that illustrate the electoral abstentions are used for pointing out beliefs, attitudes, and ideologies in several sub-domains that describes the expectations of the results and the reasons of the non-voting groups, which also trigger their voting actions.
\end{abstract}

Keywords: Metaphor; cognitive approach; political discourse; abstention.

\section{INTRODUCTION}

Abstention during an election is one of the important aspects to be addressed by election committees. Various ways are taken to encourage people to vote in the election to boost the rate of participation. In Indonesia, the famous term for non-voting people during an election is golongan putih (golput), whose literal meaning is a white group.

Mariska (2019) writes that the term golput was originally from protesting youth and students as they disagreed with the implementation of the 1971 general election. It was used specifically for those who went to the ballot box and punching a hole in the blank space, instead of on the picture of the preferred candidates to show dissatisfaction with the process. In the contemporary usage, golput (non-voters) simply refers to all those who are abstain from voting. Throughout this paper, the Indonesian term golput will be used interchangeably with the non-voting group and election abstention group.

For various reasons, the number of the non-voting groups in Indonesia has increased from one election to the next election. In the New Order era, the reasons were political. For example, this non-voting group believes that the election was not conducted based on the principles of democracy. In the 2004 election, the increasing number of non-voting groups was caused by people's disappointment with the political institution, and in the 2009 election, the most dominant factor was the inefficiency of the general election committee performance (Yanuarti 2009). However, Anam \& Somantri (2020) reports that the abstentions movement in 2019 was used by some groups of people who were marginalized, as a result of the country's uneven development affecting the vulnerable groups and minorities.

The election abstention phenomenon has been widely discussed and has been studied mainly from the perspective of political study. However, this paper attempts to investigate the abstention phenomenon from the linguistics perspective and focuses on the metaphors used in describing the phenomenon.

The description of abstention in media discourse itself is expressed in various metaphorical expressions such as below:

Gelombang Golput yang Tak Pernah Surut.

The tide of Golput that never recedes.

(Purnamasari, 2018)

Comparing election abstention to the tide shows abnormality when it is expressed as the tide that always 
rises. Generally, waves or tides in the ocean will either rise or recede. Using the term to speak about the phenomenon of election abstention has brought further consequences of something that does not happen as normally accompanied by beliefs and attitudes about the topic.

The use of metaphor in everyday discourse has been extensively examined as the focus of research since the emergence of Conceptual Metaphor Theory (CMT) of Lakoff and Johnson (1980). Since the emergence of CMT, a metaphor that was previously viewed as something ornamental now turns into something that is viewed as a conceptual and cognitive-triggered phenomenon. In principle, a metaphor is an analogy talking about one concept by using terms from another concept.

The cognitive view of metaphor also shares by Goatly (1997) who defines metaphor as thinking about one entity as it were another entity. Kövecses (2010) further explains the two domains in conceptual metaphor, the first is the source domain, which is a concrete topic that is easily understood, and the second domain is the target domain which is more abstract. For example, in a conceptual metaphor, HAPPINESS is described as UP while SADNESS is DOWN. This metaphor triggers a metaphorical expression to mean happiness as I am on top of the world while for the sadness metaphorical expression is described such as He's at the bottom of rocks. In CMT, the metaphorical expression is the linguistic expression of the conceptual metaphor (conventionally written in capital letter).

The cognitive view is developed further by CharterisBlack (2004), who emphasizes that in analyzing metaphors, three components should be combined, consisting of linguistic, cognitive, and pragmatic to achieve a comprehensive explanation in metaphors. He coins the term Critical Metaphor Analysis (CMA), which is an attempt to describe the motives and ideologies behind the use of language by using three steps adopted from the discourse analysis process, namely: identification, interpretation, and explanation of conceptual metaphors.

The focus of metaphor analysis in political discourse is to reveal the conceptual level of metaphor, as well as the ideological aspects behind certain choices that exist in conceptual metaphors. According to Wodak (2009), there are various genres of political debate, one of which is reports on various political developments in the mass media. The use of metaphor in political discourse is ubiquitous, as the metaphor suggests a persuasive impact. Chilton (2004) agrees that metaphor is important in political discourse, and Mussolf (2012) affirms that the contribution of cognitive view in metaphor will bring an additional perspective on the social context in critical discourse analysis.

There are a number studies on the use of metaphor in political discourse from various countries. Umar \& Rasul (2017) stuy various metaphors used by Nawaz Sharif in Urdu and English to uncover the ideology behind them. Antonova (2014) examines the conceptual metaphor of social conflict in Russian media. Fallah \& Moini (2016) also investigate the ideology behind the political metaphors depicting the Arab spring in newspaper editorials. Stojan \& Mijić (2019) conclude that there are no significant differences in the source domains between Croatian, American, and Italian political discourse in their study of conceptual metaphors.

There are some scholars examine metaphor in elections. Vertessen \& de Landtsheer (2005) study metaphors in a Belgian election. Đurović \& Silaški (2010) report that the marriage metaphor structures the discourse concerning the relationship between political parties in Serbia. In the case of elections in Indonesia, Budiman (2019) examines the use of war metaphors in the 2019 elections, while Adam \& Prautomo (2020) study the general image of the same elections.

There are also some scholars studying golput. Duile (2021) examines the golput campaign in fictional candidates, Nurhadi-Aldo, and reports that the language used in fictional Nurhadi-Aldo election campaign provides a new style of golput campaign since the language and political symbolism used ran counter to the political language of the ruling coalition.

Most of the studies on metaphor above focus only on elections in general or on the general aspects of politics. However, all of them agree that the use of metaphor is pervasive in political discourse. This study, however, investigates the metaphorical description of abstention during the Indonesian election 2019 in foreign media news by analyzing the source domains of the metaphors and various metaphor components contained in the studied metaphors. The foreign media news is chosen as the source for examining the outsiders' perspective on election abstention phenomena in metaphorical expression. The objective is to uncover the perspectives and attitudes of the 2019 Indonesian election non-voting groups as seen by the international community. Furthermore, this research will provide a wider alternative perspective in addressing the phenomenon of electoral abstentions which is generally only examined from political science. 


\section{METHODOLOGY}

The study uses qualitative method. It analyzes five texts of news reports in foreign media outlets as the sources of data. The qualitative method aims to get a detailed interpretation of the source domain of metaphor and its components. Cameron \& Low (1999) view metaphor analysis as a qualitative research tool that allows researchers to investigate speakers' patterns of thoughts and understandings on a given topic. This method is chosen because most methodologies used in the metaphor analysis of political discourse is a qualitative one (Ignatow \& Mihalcea, 2017).

In identifying metaphor, Charteris Black (2004, p. 35) affirms that metaphor can be identified by examining the existence of semantic clash that results in an alteration in the domain usage and can occur at either linguistic, pragmatic, or cognitive levels. Steen et al (2010) agree that to consider an expression as metaphorical, its basic meaning is in contrast to its meaning in context, thus, it triggers a cross-domain mapping between the basic meaning and its contextual meaning.

Charteris-Black' Critical Metaphor Analysis (CMA) is used in this study. There are three stages of CMA in analyzing metaphor in a discourse (Charteris-Black, 2004), and they are used in this study. The first step is metaphor identification. In this step, a close reading of the texts and highlighting the description of election abstention as the target domain are conducted. If there are descriptions of the election abstention aspects in metaphorical expressions, they are classified as metaphors. The next step is metaphor interpretation. This is conducted by identifying the source domain of the metaphors used in order to get ideas on how the metaphors used are related to the cognitive and pragmatic factors that determine them. This stage is also used for identifying the conceptual metaphors. The third step is metaphor explanation. This is conducted by examining the social context in which the metaphors are produced and their persuasive roles. This will lead to identifying the discourse function of metaphors and establishing the ideological and rhetorical motivations.

The metaphor interpretation and explanation are presented in cluster forms in the discussion and are based on the essential aspects of each conceptual metaphor. Kövecses (2003) affirms various components that interact in metaphor composition, such as experiential basis; source domain to target domain mapping and its relationship; The basic and the extra conceptual correspondences and mapping; inferences, and: the possibility of the cultural integration in metaphorical expression.

\section{FINDINGS AND DISCUSSION}

Gibbs (2010) agrees that the use of a metaphorical expression in language can cause a change in how we understand and perceive various topics, and it is also used as a mode of reasoning (Chilton, 2004). Thus, describing abstention phenomena in an election by using metaphor is intended to provide particular reasoning that highlights particular aspects and components of each metaphorical expression.

The discussion of the findings will be presented based on the highlighted components in metaphors and relate the metaphor with the discourse context including the potential inferences and entailments.

The metaphors of election abstention are presented in table 1 .

Table 1. Metaphorical Expressions on Election Abstention

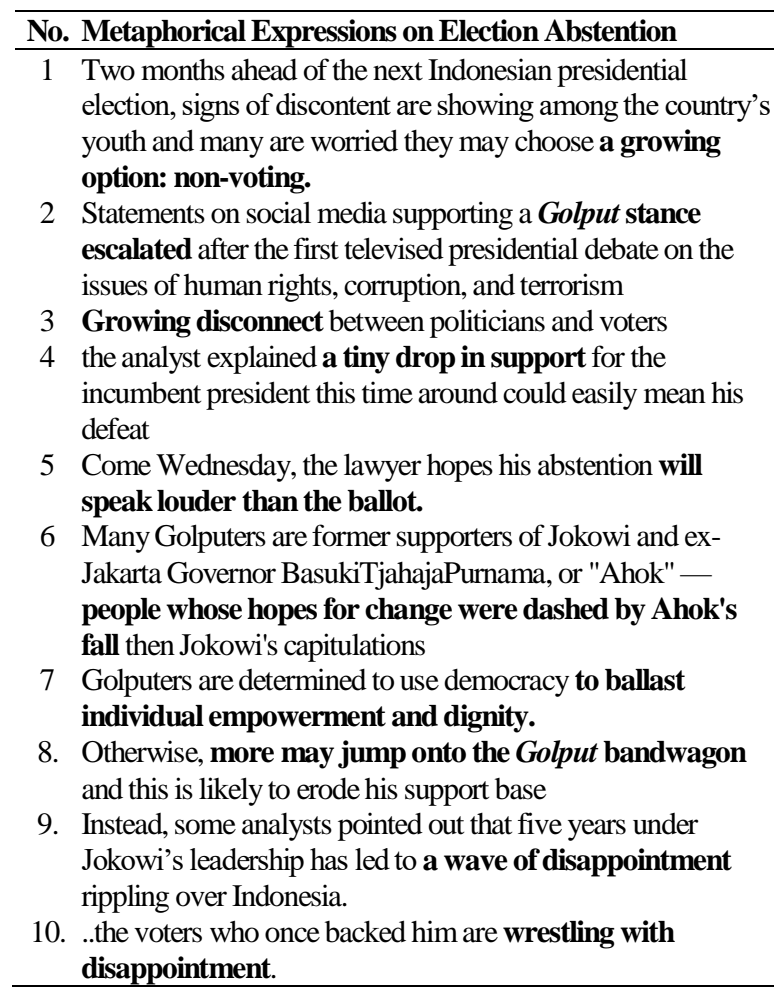

\section{Orientational and Ontological Metaphor}

Lakoff and Jonhnson (1980) describe three types of conceptual metaphor, i.e: The structural metaphor, ontological metaphor, and orientational metaphor. Orientational metaphors allow speakers to make a set of target concepts coherent through some basic human spatial orientations, such as up-down, in-out, centerperiphery, and the like.

The increasing number of non-voters during the election was addressed using one of the orientational metaphors, i.e: the conceptual metaphor of MORE IS 
UP; LESS IS DOWN. The vertical or horizontal movement is used in some of the metaphors describing abstention to describe the increasing numbers of the particular topic discussed.

During the 2019 election, there are predictions of the increasing number of non-voters. Extract 1 below describes the phenomena using a metaphorical expression of "growing option".

\section{Extract 1:}

Two months ahead of the next Indonesian presidential election, signs of discontent are showing among the country's youth and many are worried they may choose a growing option: non-voting. (Widianto, 2019)

A growing option is considered as metaphorical because it expresses the non-voting action as something that grows. It compares the phenomenon to the living thing that can grow vertically to an upward position. The choice of using the "growing option" referring to the increasing number of non-voters suggests that time after time, for some reasons, some people have chosen to take the option. In particular, Extract 1 above highlights that many are worried about how this growing option is chosen by the Indonesian youth during the election.

The same conceptual metaphor also used in extract 2 below. It uses the word "escalate" that infers an upward movement, that is, the increasing number of statements to support golput in social media after the first Presidential debate.

\section{Extract 2:}

Statements on social media supporting a Golput stance escalated after the first televised presidential debate on the issues of human rights, corruption, and terrorism. (Lane \& Hui, 2019)

The word "escalate" refers to an entity that physically moves to an upward position. The choice of the word "escalated" suggests a rapid increase and going vertically up. This particular choice of metaphor infers a significant move in numbers which, in the case in extract 2 above, refers to the increasing number of social media statements that support the non-voting option. The first presidential debate that is mentioned in extract 1 above refers to the first presidential debate that aired on January 17, 2019.

In extract 3 below, disappointment as the reason of choosing abstention is generally described as politicians' failure in fighting for the voters' aspiration.

Extract 3:

"Growing disconnect between politicians and voters." (Fettling, 2019)
The metaphorical use of "growing disconnect" suggests that there has been a failure between the politicians and the voters, and the failure is increasing. The choice "disconnect between politicians and voters" also implies that more politicians are not delivering what they have promised and fighting for what people need. It also implies that there is an important need, that is, listening to what people aspire and fighting for that. If this need is taken care of, the non-voting group can eventually feel that its voice is heard. The use of the word "growing" to modify disconnect implies that the disconnection grows bigger and bigger, and the politicians, particularly those how are in the House of Representatives, should address it.

In the Conceptual metaphor, MORE is UP; LESS is DOWN, the linguistics expression for vertically downward position suggests a decrease in numbers as seen in extract 4 below:

"the analyst explained a tiny drop in support for the incumbent president this time around could easily mean his defeat". (Promchertchoo, 2019)

The phrase "a tiny drop in support" refers to the potential decreasing numbers of non-voters who will not vote for the incumbent. The words "tiny drop" particularly imply that the assumed margin between who will vote again for the incumbent and who will vote against the incumbent is very close. Thus, when more and more voters choose the option of abstention, their choice may affect the election result, which will not be in favor of the incumbent. Extract 3 above shows that the effect of the increasing rate of nonvoters can change the result of the election since there are only two candidates who run for the presidency.

The types of ontological metaphors are also used for describing abstention and expressing the expectation of the non-voters for the outcome of their action. In CMT, Lakoff and Johnson (1980) include personification as an ontological metaphor, which is a cross-domain mapping where an entity is described as a person. Extract 5 below describes the hope that the abstention is expected to deliver what concerns that the non-voters group are trying to raise.

Extract 5:

"Come Wednesday, the lawyer hopes his abstention will speak louder than the ballot".(Promchertchoo, 2019)

The phrase "speak louder than ballot" assigns a person's action to an inanimate situation as it reflects an expectation that the non-voting action will give a stronger impact than voting in the election. The decline of their trust in the government and/or the election itself is/are expressed through the abstention in the election. 
The metaphor above particularly chooses the metaphorical phrase "speak louder than ballot", which means that their option is expected to be acknowledged by the authority.

In extract 1 to extract 5 above, the ontological metaphor is used for describing the attitude towards three aspects of the election abstention. The first is the aspect of the increasing number of non-voters, the second is the effect of the non-voting action on the presidency contestation and the third is the expectation towards being non-voters.

\section{The Importance of Mental Image in Metaphoric Transfer}

One essential aspect in CMT is the activation of embodied experience. Lakoff (2012) asserts that conceptual metaphors assemble a large amount of mental perception. Gibbs \& de Macedo (2010) also describe that mental imagery as one of the embodied experiences in the metaphoric transfer. Furthermore, Golding (2015), who discusses the significance of the mental image involvement in metaphorical language, highlights that images, sounds, smells, and feelings are also some aspects to which the creative metaphors are connected.

The aspect of disappointment and the expectation of results by being non-voters is described in metaphor by using the significance of the embodied experience component in the forms of a mental image can be seen in extracts 6 below

\section{Extract 6:}

"Many Golput-ers are former supporters of Jokowi and ex-Jakarta Governor Basuki Tjahaja Purnama, or "Ahok" - people whose hopes for change were dashed by Ahok's fall then Jokowi's capitulations". (Fettling, 2019)

Extract 6 above is related to the situation around what happened to the ex-Jakarta Governor Basuki Tjahaya Purnama who was also the vice Governor when Jokowi won the Jakarta election. When Ahok was sentenced to two years in prison for a blasphemy case, many of their supporters lost hopes.

The choice of a particular expression "dashed by" triggers mental imagery of something that is hit hard. In this particular context, the fall of Ahok is described as a property that hit the hope of the voters. The use of this particular metaphor is to provide a more vivid mental image. According to Thibodeau, Hendricks, \& Boroditsky (2017), metaphors affect the way people think about a specific thing and are constructed by their cognitive process which is related to that specific thing. Thus, the use of "dash' in the metaphor above is intended to create a sense of a strong hit.
In extract 7 below, the action of abstention is described as ballast a load that can carry a steadiness and stability: Extract 7:

"Computers are determined to use democracy to ballast individual empowerment and dignity". (Fettling, 2019)

In extract 7, it entails that democracy has not made the non-voters feel stable in their sense of empowerment and dignity. The type of embodied experience used in this metaphor is also a perception of the mental image of the stability of a ballasted property. The most basic literal meaning of ballast as a noun is used in the nautical field and refers to any heavy material carried in a vessel to provide stability.

In extract 7, the basic meaning of the word ballast can produce another meaning when it is used as a metaphor. The polysemous effect of the word is a product of the metaphorical use. Lyons (1977) writes that metaphorical creativity can produce polysemy. Lopukhina, et. al. (2018) agree that metaphor can trigger polysemy. They added further that in metaphor, a new sense is derived from the literal sense of a word through metaphorical mapping.

Extract 6 and Extract 7 above conveys the attitudes and beliefs about the description of how the non-voters feel, in particular to the issue of Ahok's blasphemy case and how non-voters' sense of empowerment and dignity has not been recognized. These two topics become highlighted points that are also addressed by the foreign media news to the non-voting phenomenon.

\section{Cultural Context in Conceptual Metaphor}

A cultural context term is used in extract 8 below. The golput bandwagon is used as the place where more and more people will join and jump onto the wagon. The choice of using the word "bandwagon" reflects an additional sphere. (Kövecses, 2005) affirms that cultural variation in metaphor can be found within a culture or across cultures. Littlemore \& Low (2006) suggest the sources of cross-cultural metaphor variation, i.e: History and behavior, social organization, and the physical environment

\section{Extract 8:}

Otherwise, more may jump onto the Golput bandwagon and this is likely to erode his support base. (Lane \& Hui, 2019)

The term bandwagon used in the metaphor above is not a universal term. Treguer (n.d.) explains that the phrase "jump on the bandwagon" means joining the popular or winning side. The word "bandwagon" denotes a popular party, faction, or cause that attracts growing 
support. He finds that the earliest use of the term is found in the New Orleans Weekly Delta (New Orleans, Louisiana), dated February 15, 1847. Thus, the cultural aspects of the term "bandwagon" used in extract 5 above can be traced back to the history of the original use of the term that was originally not used in the political sphere.

The use of the golput bandwagon implies that there have been numbers of people supporting the view. As Schmitt-Beck (2015) explains, the term "bandwagon effect" indicate "a phenomenon of public opinion impinging upon itself (sometimes also referred to as "contagion effect")." The use of the particular metaphor "jump onto the Golput bandwagon" in extract 8 above, not only puts more emphasis on the political sphere of the metaphorical use relating to its context, but also creates an image of a group of people that share the same choice.

\section{Highlighted Aspects, Attitudes, and Beliefs behind metaphors.}

The elements or characteristics of the source domain in conceptual metaphor are not always mapped thoroughly, but only some essential elements are needed. Landau, Robinson, \& Meier (2013) agree that target domain - source domain mapping will highlight some elements when at the same time also downplay other elements. As seen in the use of metaphor to describe the reason for disappointment in extract 9 below, 'wave" as metaphor source domain is used to describe the non-voters disappointment.

Extract 9:

"Instead, some analysts pointed out that five years under Jokowi's leadership has led to a wave of disappointment rippling over Indonesia". (Promchertchoo, 2019)

The choice of the particular metaphor "wave of disappointment" infers a momentum that spreads from an epicenter and moves towards a broader area. This entails the disappointment which is viewed as something that grows bigger and bigger over time. It implies that the wave is moving from one point to an extended point or area. The particular choice of the verb "rippling" strengthens the previous phrase and implies that originally the disappointment will only start from one particular and contained point, but over time, it spreads to a wider area. In an analogical relation to the target domain in extract 9 above, it suggests that the disappointment only starts from a fairly small number of people, but then it becomes cumulatively high over a period of time. In this extract, a wave that moves from one point and spread into the broader area is the highlighted element. Whereas, other elements of a wave, such as its liquidity, its up and down movement are underestimated.
The highlighted element of the source domain in the extract below is the physical/mental struggle against something; the non-voters are expressed as those who are wrestling with disappointment.

Extract 10:

"...the voters who once backed him are wrestling with disappointment". (Walton, 2019)

Non-voters are expressed as fighting wrestlers. They are described as the ones that have to fight against other wrestlers. In this extract, other wrestlers is "disappointment". The disappointment refers to the commitment the politician made in his previous campaign, which, according to non-voters, have not been fulfilled. The choice of the metaphor "wrestling with disappointment" implies the struggle that nonvoters have faced, that is, fighting against their disappointment. The use of metaphorical word "wrestling" not only triggers the emergence of a conceptual image of the fight that a wrestler must face, but also infers some other aspects related to the source domain, such as a vivid description of a challenging thing that they have to fight against, the physical and mental strength needed, etc. Meanwhile, other aspects of wrestling itself, such as the ring, crowd of spectators, referees, and judges as seen in wrestling matches, are not highlighted in the above metaphor.

The particular choice of using a specific source domain of metaphors, particularly in political discourse, is not just intended as an ornamental linguistics expression. The combination of various components that constructs metaphors enables metaphorical expressions to be used for delivering a vivid description of a particular concept, in this case, the abstention phenomena. The metaphor about the extent of the abstention rate, the reason for being non-voters, and the expectation and effect of the non-voters on democracy are described with a particular choice of metaphor that highlights particular conceptual aspects.

The results show the use of metaphor in political news particularly in the election is pervasive. The metaphors provide salient analogical reasoning which in turn delivers a vivid image on a particular aspect. The use of metaphorical expressions confirms that metaphor particularly in political discourse is intended to carry an ornamental use of expressions, as well as to provide a descriptive picture of the target domain and links our conceptual way of thinking from the source domain use.

As written by Knowles \& Moon (2006), people use metaphor not only for expressing what people think and feel about something but also for explaining what a particular thing is like in delivering a message more creatively. The metaphorical use by foreign media in 
describing various aspects of the abstention phenomenon in Indonesian elections shows their attitudes and beliefs in addressing each aspect of abstention with a particular source domain.

\section{CONCLUSION}

Various source domains are used for making a metaphorical voice about abstentions in the 2019 Indonesian elections. Similarly, there are several aspects of election abstention that become the subtarget domain of the metaphor. Some of them are the increasing number of the non-voters described using the ontological metaphor of UP is MORE and DOWN is LESS, and the reason of being non-voting supporters, described using the source domain of a struggling wrestler and a moving wave. Besides that, expectations for the outcome of being a non-voter are described as a weighing instrument of dignity and empowerment. In constructing metaphorical expressions, the mapping of the source domain to each subtarget domain is combined with various components of metaphors.

The use of metaphorical expressions on several aspects of non-voting has shown that metaphors are not only within linguistic aspects, but also reflect beliefs and attitudes towards certain topics, in this case, the abstention election. By capturing the foreign media description of abstention phenomena, this study shows the 'outsiders' view on the non-voting phenomenon in Indonesian elections that highlights how the nonvoters' option is seen as a better option for marginalized people. Furthermore, news reports on abstention show how the non-voting people have been coping with a disappointment of political commitment, and send a message of how politicians are expected to listen more to their voters. The implication of this study is that understanding the cause and the expectation of the non-voters will become a valuable input for politicians and the election committee to address the issue of abstention. Addressing this issue will be able to bring back the non-voters' trust in the election, and this will improve people's participation in the election. Improved election participation will eventually change the perception of foreign observers that non-voting has not become a better option anymore.

\section{REFERENCES}

Adam, M., \& Prautomo, A. (2020). A mammoth logistical challenge with slight hiccups: The metaphorical image of Indonesian election 2019 (Proceedings of the 4th International Conference on Language, Literature, Culture, and Education (ICOLLITE 2020)). Advances in Social Science,
Education and Humanities Research, 509, 456462. https://dx.doi.org/10.2991/assehr.k.201215. 072

Anam, M. S., \& Somantri, G. R. (2020). Abstentions in 2014 and 2019 Indonesian elections: Case study of pro-democracy activists. Simulacra, 3(1), 27-42. https://doi.org/10.21107/sml.v3i1. 7307

Antonova, T. G. (2014, October). Social Conflict through Conceptual Metaphor in Media Discourse. Procedia - Social and Behavioral Sciences, 154, 368-373. https://doi.org/10.1016/j.sbspro.2014.10.165

Budiman, A. (2019). War metaphors in political contestation prior to 2019 presidential election. (Proceedings of the 6th International Conference on Community Development (ICCD 2019). Advances in Social Science, Education and Humanities Research, 349, 43-46. https://doi.org/ 10.2991/iccd-19.2019.12

Cameron, L., \& Low, G. (1999). Metaphor. Language Teaching, 32(2), 77-96. https://doi.org/10.1017/ S0261444800013781

Charteris-Black, J. (2004). Corpus Approaches to Critical Metaphor Analysis. New York: Palgrave Macmillan. https://doi.org/10.1057/9780230000 612

Chilton, P. (2004). Analysing political discourse: Theory and practice. London: Routledge.

Duile, T. (2021). Challenging hegemony: NurhadiAldo and the 2019 election in Indonesia. Journal of Contemporary Asia, 51(4), 537-563. https://doi. org/10.1080/00472336.2020.1748896

Đurović, T., \& Silaški, N. (2010). Metaphors we vote by: The case of marriage in contemporary Serbian political discourse. Journal of Language and Politics, 9(2), 237-259. https://doi.org/ 10.1075/jlp.9.2.04dur

Fallah, N., \& Moini, M. R. (2016). A critical metaphor analysis of Arab uprisings in "The Washington Post" and "Keyhan" editorials. Metaphor \& the Social World, 6(1), 79-102. https://doi.org/10. 1075/msw.6.1.04fal

Fettling, D. (2019, April 16). Indonesia's golput movement exposes Australian stereotypes of our nearest neighbour. $A B C$ News. https://www.abc. net.au/news/2019-04-16/indonesias-golputmovement-exposes-australian-stereotypes/11003 476

Gibbs, R. W., \& de Macedo, A. C. P. S. (2010). Metaphor and embodied cognition. DELTA: Documentação de Estudos em Lingüística Teórica e Aplicada, 26(SPL. ISS.), 679-700. https://doi. org/10.1590/S0102-44502010000300014

Goatly, A. (1997). The language of metaphors. London: Routledge. 
Golding, A. (2015). Mental imagery and metaphor. Porto Alegre, 8(1), 20-32. https://doi.org/ http://dx.doi.org/10.15448/1984-4301.2015.1.19 608

Ignatow, G., \& Mihalcea, R. (2017). Metaphor Analysis. In G. Ignatow \& R. Mihalcea (Eds.), Text mining: A guidebook for the social sciences ( $\mathrm{pp}$. 96-103). https://doi.org/10.4135/9781483399782. n9

Knowles, M., \& Moon, R. (2006). Introducing Metaphor. New York: Routledge.

Kövecses, Z. (2003). Language, figurative thought, and cross-cultural Comparison. Metaphor \& Symbol, 18(4), 311-320. https://doi.org/10.1207/ S15327868MS1804_6

Kövecses, Z. (2005). Metaphor in culture: Universality and variation. New York/Cambridge: Cambridge University Press.

Kövecses, Z. (2010). Metaphor: A practical introduction. London: Oxford University Press.

Lakoff, G., \& Johnson, M. (1980). Metaphor we live by. Chicago: University of Chicago Press.

Lakoff, G. (2012). Explaining Embodied Cognition Results. Topics in Cognitive Science, 4(4), 773785. https://doi.org/10.1111/j.1756-8765.2012. 01222.x

Landau, M., Robinson, M., \& Meier, B. (Eds.). (2013). The Power of Metaphor: Examining Its Influence on Social Life. Washington, D.C: American Psychological Association.

Lane, M., \& Hui, Y. F. (2019, January 31). Indonesia election: Joko Widodo's latest challenge may come from people refusing to vote. South China Morning Post. https://www.scmp.com/weekasia/opinion/article/2184317/indonesia-electionjoko-widodos-latest-challenge-may-comepeople

Littlemore, J., \& Low, G. (2006). Figurative Thinking and Foreign Language Learning. New York: Palgrave Macmillan. https://doi.org/10.1057/978 0230627567

Lopukhina, A., Laurinavichyute, A., Lopukhin, K., \& Dragoy, O. (2018, February). The mental representation of polysemy across word classes. Frontiers in Psychology, 9, 1-16. https://doi.org/ 10.3389/fpsyg.2018.00192

Lyons, J. (1977). Semantics (Vol. 2). Cambridge: Cambridge University Press.

Mariska, M. A. (2019, April 10). Golput and Its Implications. RSIS Commentary (No. 068). RSIS, Nanyang Technological University.

Mussolf, A. (2012). The study of metaphor as part of critical discourse analysis. Critical Discourse Studies, 9(3), 301-310. https://doi.org/https://doi. org/10.1080/17405904.2012.688300

Promchertchoo, P. (2019, April 15). To vote or not to vote, that is the question for many Indonesians ahead of election. Channel News Asia. https://www. channelnewsasia.com/news/asia/to-vote-not-tovote-question-for-many-indonesian-voterselection-11447492

Purnamasari, D. (2018, August 28). Gelombang golput yang tak pernah surut [The never-receding waves of golput]. Tirto.Id. https://tirto.id/gelombanggolput-yang-tak-pernah-surut-cVnc

Schmitt-Beck, R. (2015). Bandwagon Effect. The International Encyclopedia of Political Communication. Willey Online Library. https://onlinelibrary.wiley.com/doi/full/10.1002/9781118541 555.wbiepc015

Steen, G. J., et al. (2010). A method for linguistic metaphor identification. Amsterdam: Benjamins.

Stojan, N., \& Mijić, S. N. (2019). Conceptual metaphors in political discourse in Croatian, American and Italian Newspapers. Academic Journal of Interdisciplinary Studies, 8(1), 69-76. https://doi.org/10.2478/ajis-2019-0007

Thibodeau, P. H., Hendricks, R. K., \& Boroditsky, L. (2017, November 1). How Linguistic Metaphor Scaffolds Reasoning. Trends in Cognitive Sciences, 21, 852-863. https://doi.org/10.1016/ j.tics.2017.07.001

Treguer, P. (n.d.). Origin of 'To Jump on The Bandwagon.' https://wordhistories.net/2018/01/ 22/jump-bandwagon-origin/

Umar, L., \& Rasul, S. (2017). Critical metaphor analysis: Nawaz Sharif and the myth of a golden time. NUML Journal of Critical Inquiry, 152(2), 78-102. https://www.numl.edu.pk/journals/subjects/1566300771article\%205.pdf

Vertessen, D., \& de Landtsheer, C. (2005, April 1419). A metaphorical election style? Patterns of symbolic language use in Belgian politics [Conference presentation]. ECPR Joint Sessions Workshop "Metaphor in Political Science", Granada, Spain. https://seis.bristol.ac.uk/ potfc/ Granada/Papers/Vertessen.pdf

Walton, K. (2019, April 9). "Golput": Why a number of Indonesians will not be voting. Al Jazeera. https://www.aljazeera.com/news/2019/04/numb er-indonesians-voting-190408010647247.html

Widianto, S. (2019, January 29). For Indonesian Millennials, Abstentions Are an Appealing Option. Voice of America. https://www.voanews.com/ a/Indonesian-elections/4763187.html

Wodak, R. (2009). Language and Politics. In J. Culpeper, F. Katamba, \& P. Kerswill (Eds.), English Language: Description, Variation and Context (pp. 576-593). Hampshire: Palgrave Macmillan.

Yanuarti, S. (2009). Golput dan pemilu di Indonesia [Golput and election in Indonesia]. Jurnal Penelitian Politik, 6(1), 21-32. https://doi.org/ 10.14203/jpp.v6i1.519 